peripheral intravenous catheter insertions in children. Pediatrics 2004;II3(3):e217-20.

3. Eichenfield LF, Funk A, Fallon-Friedlander S, et al A clinical study to evaluate the efficacy of ELA-Max ( $4 \%$ liposomal lidocaine) as compared with eutectic mixture of local anesthetics cream for pain reduction of venipuncture in children. Pediatrics 2002;109:1093-9.

4. Kleiber C, Sorenson M, Whiteside K, et al. Topica anesthetics for intravenous insertion in children: randomized equivalency study. Pediatrics 2002;1IO (4):758-6r.

5. Koh JL, Harrison D, Myers R, et al. A randomized double-blind comparison study of EMLA and ELAMax for topical anesthesia in children undergoing intravenous insertion. Pediatr Anaesth 2004; I4: 977-82.

6. Walco GA, Burns JP, Cassidy RC. The ethics of pain control in infants and children. In: Schechter NL, Berde CB, Yaster M, editors. Pain in infants, children, and adolescents. 2nd ed. New York: Lippincott Williams \& Wilkins; 2003. p. 157-68.

DOI:I0.1503/cmaj.I050I54

\section{[The authors respond:]}

Conrad Fernandez and Gerri Frager's claim that it is wrong to expose patients to "unnecessary procedural pain" would be correct if in the practice of emergency pediatrics children routinely received EMLA, ${ }^{\circledR}$ Ametop ${ }^{\circledR}$ or similar products. In reality, most venipunctures in Canadian pediatric emergency departments are performed without any local anesthetics. In initiating this study, the question that our research ethics board and ourselves had to ask was "What is the routine, standard practice in our emergency department"? In our hospital, children did not routinely receive topical anesthesia. The reason was that it was believed to interfere with cannulation success. Since previous studies had not addressed this question, a placebo-controlled trial was necessary to disprove this belief.

\section{Anna Taddio}

\section{Gideon Koren}

The Hospital for Sick Children

Toronto, Ont.

DOI:Io.1503/cmaj.1050226

\section{Getting a grip on waiting}

\section{lists}

David Hadorn's analysis ${ }^{1}$ fails to distinguish between waiting lists for diag- nostic procedures (such as MRI) and those for therapeutic procedures. Diagnostic information is often required to confirm the presence of disease and assess its severity, and only when this information becomes available can the patient be appropriately queued for treatment. Long wait times for diagnostic tests are counterproductive and costly, both to the patient in terms of morbidity and disease progression and to the medicare system in terms of wasteful use of "second best" tests. A six-month wait for an MRI to confirm suspected multiple sclerosis is no more reasonable than a similar wait for a blood test to confirm suspected anemia. The Western Canada Waiting List project failed to statistically validate its MRI prioritization tool and has not endorsed it for general use. MRI prioritization does not work well simply because the severity of disease (and therefore the urgency of the test) is not accurately known until the test is done. The only practical and ethical way to address MRI wait lists is to provide adequate capacity for demand. The Alberta Imaging Advisory Committee pegged that capacity at 62 exams/Iooo people/ year. ${ }^{2}$ Alberta is the only province to approach that capacity. Sadly, Ontario, which maintains an absolute statutory monopoly over MRI services, provides for only half the needed capacity.

\section{Leonard Avruch}

Supervising Radiologist, MRI

Ottawa Hospital (General Campus)

Former Chair, MRI Panel, Ontario

Wait List Project

Former member, MRI/CT Expert

Panel, Ontario Wait Time Strategy Ottawa, Ont.

\section{REFERENCES}

I. Hadorn D. The Chaoulli challenge: getting a grip on waiting lists [editorial]. $C M A J$ 2005;I73(3):27I-3

2. Companion to Alberta Diagnostic Imaging-Within a Framework of Reform, Imaging Advisory Committee, Calgary, Alberta, 2002.

DOI:I0.1503/cmaj.1050180

\section{[The author responds:]}

I agree that MRI and other diagnostic procedures are not well-suited to the priority criteria approach. However, I don't agree that "the only practical and ethical way to address MRI wait lists is to provide adequate capacity for demand."

Demand bears no necessary relationship to need or benefit, and convincing evidence that MRIs lead to improved health outcomes (e.g., longer life, less pain) should be provided before MRI supplies are increased. Unfortunately, the radiology research community has been slow to produce (or even to seek) such evidence. Indeed, we were unable to find any relevant studies in the MRI literature during the initial portion of the Western Canada Waiting List project. This was some years ago, but I am not aware that the situation has changed much in the interim.

\section{David Hadorn}

Former Manager, New Zealand

Priority Criteria Project

Former Research Director of the

Western Canada Waiting List Project Richmond, Calif.

DOI:I0.1503/cmaj.I050202

\section{Corrections}

The DOI attached to a recent letter ${ }^{1}$ should have been DOI:I0.1503/cmaj .1050093.

\section{REFERENCE}

I. Lexchin J. A hypertensive snow bird [letter]. CMAJ 2005;I73(II):I357.

DOI:I0.1503/cmaj.051682

In a recent research paper, ${ }^{1}$ the answers to the individual scale items on the Hamilton Depression Rating Scale in Appendix I were omitted. The correct appendix is included here (see page 208).

\section{REFERENCE}

I. McIntyre RS, Konarski JZ, Mancini DA, et al. Measuring the severity of depression and remission in primary care: validation of the HAMD-7 scale. CMAJ 2005;I73(II). DOI:Io.I503/cmaj.050786

DOI:I0.I503/cmaj.051683 